\title{
Is Diet-shifting Facilitated by Modulation of Pancreatic Enzymes? Test of an Adaptational Hypothesis in Yellow-rumped Warblers
}

\author{
M. Eugenia Ciminari, ${ }^{1}$ Daniel AfiK, ${ }^{2}$ William H. Karasov, ${ }^{3,4}$ and Enrigue Caviedes-Vidal ${ }^{1}$ \\ ${ }^{1}$ Unidad de Investigaciones en Ciencias Biológicas, Universidad Nacional de San Luis, 5700 San Luis, Argentina; \\ ${ }^{2}$ Department of Biology, University of Haifa at Oranim, Oranim, Tivon 36003, Israel; and \\ ${ }^{3}$ Department of Wildlife Ecology, University of Wisconsin-Madison, Madison, Wisconsin 53706, USA
}

\begin{abstract}
Many birds exhibit seasonal switches in diet and thus alter nutrients predominating their food intake. We tested for dietary modulation of pancreatic enzymes in Yellow-rumped Warblers (Dendroica coronata), a species for which such dietary changes are documented. Birds were fed three diets formulated from either fruit, insect, or seed. We predicted that pancreatic carbohydrase amylase, and the proteases trypsin and chymotrypsin, would be modulated in direct correlation with relative levels of
\end{abstract}

${ }^{4}$ Address correspondence to this author. Department of Wildlife Ecology, 226 Russell Laboratories, 1630 Linden Drive, University of Wisconsin, Madison, Wisconsin 53706, USA. E-mail: wkarasov@facstaff.wisc.edu dietary carbohydrate and protein, respectively. In contrast to the prediction, there was no significant dietary effect on activities of amylase and chymotrypsin, and a significant change in trypsin activity (highest on seed diet) occurred in the wrong direction with regard to the prediction. Considering the statistical power of our tests, we conclude that Yellow-rumped Warblers represent a case of only modest ability, at best, to modulate pancreatic enzymes. For some diets, especially high-starch diets that they digest relatively poorly and on which they tend to lose body mass, they may lack sufficient enzyme and hence are constrained in their dietary niche.

Some birds respond to seasonal changes in food availability by switching to alternativly available 
foods, thus altering the nutrient composition of the diet. Because nutrients differing in chemical structure are digested along distinct digestive pathways (Karasov and Hume 1997), ability to modulate different digestive enzymes may permit or constrain such dietary flexibility. It has been hypothesized that animals modulate, rather than maintain high constituitive levels of specific enzymes, because the metabolic expense of synthesizing and maintaining large amounts of digestive enzymes would be wasted by animals feeding on diets with very low levels of substrates for those enzymes (Karasov and Hume 1997). Thus, the a priori expectation for animals with biochemical lability is that, for dietary components such as carbohydrates, protein, and lipid, there will be a positive relationship between their level in the diet and presence or amount of gut or pancreatic enzymes necessary for their breakdown.

Although diet switching is common among wild birds, until recently there were no tests of that hypothesis for pancreatic digestive enzymes in wild avian species. In coordination with another study of enzymatic modulation in Pine Warblers (Dendroica pinus) (Levey et al. 1999), we tested for dietary modulation of three pancreatic enzymes in congeneric Yellow-rumped Warblers (Dendroica coronata): the carbohydrase amylase and the proteases trypsin and chymotrypsin. There are other major pancreatic enzymes that we did not test, including lipase and the proteases collagenase, elastase, and carboxypeptidase(s). Yellow-rumped Warblers are good candidates for a test for dietary modulation of digestive enzymes because they are insectivorous during their breeding season in northern regions of North America, whereas during migration and while wintering their diet changes to include a large proportion of fruit (51-78\%; Yarbrough and Johnston 1965) and even, apparently, nectar (Gryj et al. 1990) in some locales.

To examine the hypothesis, we assessed pancreatic enzyme activity in Yellow-rumped Warblers following habituation to three diets with different proteincarbohydrate-lipid contents: fruit-based, insectbased, and seed-based (Afik et al. 1995). The proteases we measured, trypsin and chymotrypsin, are the key enzymes that break down the polypeptides that result from gastric pepsin digestion into shorter peptide fragments. The carbohydrase amylase breaks down storage carbohydrates in plants (amylose, amylopectin) and animals (glycogen). In chickens (Gallus gallus domesticus; Imondi and Bird 1967, Hulan and Bird 1972), and in laboratory rats, levels of amylase and proteases change in proportion to the dietary content of their respective substrates, and increases of $5 \times$ have been observed for amylase, trypsin, and chymotrypsin activity (Brannon 1990). Thus, on the basis of protein contents of our diets, we tested the prediction that trypsin and chymotrypsin activities would be at least twice as high in
Yellow-rumped Warblers fed the insect diet, compared with the other two diets. Note that we predict a specific upward modulation of proteases relative to amylase, rather than nonspecific modulation in which activities of all enzymes are increased (Karasov and Hume 1997). Forming a prediction for amylase is not straightforward because all diets have fairly similar starch or glycogen contents (range 817\%; Afik et al. 1995). However, if the signal for modulation of amylase were total dietary carbohydrates, as is the case in rats and chickens (Karasov and Hume 1997), then we would expect that amylase activities would be at least twice as high in Yellowrumped Warblers fed the fruit diet, compared with the other two diets.

Methods.-Yellow-rumped Warblers were mist-netted during fall migration near Chippewa Falls, Wisconsin $\left(45^{\circ} 00^{\prime} \mathrm{N}\right.$ latitude, $91^{\circ} 30^{\prime} \mathrm{W}$ longitude), and transferred to our laboratory in Madison where they were banded and housed in individual cages $(60 \times$ $45 \times 33 \mathrm{~cm})$ under constant light cycle $(12: 12 \mathrm{~h}$ lightdark cycle) and temperature $\left(21^{\circ} \mathrm{C}\right)$. We maintained the birds on a formulated banana-based diet made after (Denslow et al. 1987), supplemented with four to five mealworms (Tenebrio molitor) and water ad libitum daily.

For the experiments, performed 1 year after capture, birds were given one of three formulated diets prepared the same way as the maintenance diet, but differing in the major ingredients to resemble possible natural food types that Yellow-rumped or Pine warblers consume. We assigned at least seven birds to each diet, which should provide sufficient power to discriminate enzyme activities that differ by a factor of 2, based on sample size tables in (Cohen 1988) and assumptions about standard deviations (up to $75 \%$ of respective mean values), and error risks for Type I errors ( $\alpha=0.1$ for a priori prediction) and Type II errors $(\beta=0.2)$. Experimental diets, prepared as described in (Afik et al. 1995), were composed primarily of the following foods and had the following approximate nutrient concentrations: fruit diet (banana, identical to the maintenance diet; $73 \%$ carbohydrate $/ 16 \%$ protein $/ 5 \%$ lipid), insect diet (mealworms; 10/53/32\%), seed diet (husked sunflower seeds; $17 / 21 / 45 \%$ ). Birds ate their respective diets for seven days, during which time body mass was monitored. Birds fed the fruit- and seed-based diet were not provided with any insect material. We chose 7 days because changes in pancreatic enzyme contents are apparent within $24 \mathrm{~h}$ after a dietary change in rats and chickens, and in rats continue for 5-7 days after the diet change when new steadystate levels are reached (Karasov and Hume 1997).

Nonfasted birds were anesthetized using methoxyflurane, and the pancreas was carefully excised, divided longitudinally into two parts, weighed and immediately frozen in liquid $\mathrm{N}_{2}$. Pancreas were later thawed and homogenized for $30 \mathrm{~s}$ 
using an Omni 5100 (setting 6) homogenizer in phosphate buffer $(0.05 \mathrm{M}, \mathrm{pH} 6.9$, and containing $7 \mathrm{mM}$ $\mathrm{NaCl})$ at $0^{\circ} \mathrm{C}$. We measured activity in whole homogenates because we found that a good amount of activity (amylase and trypsin) in House Sparrow (Passer domesticus) pancreas remained in both the formed pellet and the supernatant after centrifugation $\left(14,000 \times \mathrm{g}\right.$ for $30 \mathrm{~min}$ at $\left.8^{\circ} \mathrm{C}\right)$.

Activity of amylase (EC 3.2.1.1; EC numbers are from hierachical classification of the International Enzyme Commission) was measured by a modification of the 3,5-dinitrosalicylate method (Dalquist 1962, Hjorth 1979). Ten-microliter aliquots were incubated with $2 \%$ potato starch (Sigma no. S2630) at $40^{\circ} \mathrm{C}$ for $3 \mathrm{~min}$. The reaction was terminated by the addition of $1 \mathrm{~mL}$ dinitrosalycilate reagent. The tubes were immersed in boiling water during $10 \mathrm{~min}$ and the absorbance was read at $530 \mathrm{~nm}$. The enzyme solution was diluted so that the final reaction mixture will contain $<2.0 \mu \mathrm{U}$. One amylase unit (U) represents the amount of amylase that liberates $1 \mathrm{~mol}$ of free reducing groups in a $2 \%$ starch solution in $1 \mathrm{~min}$ at $40^{\circ} \mathrm{C}$. Duplicates of each sample were assayed and the activity is reported as the mean \pm 1 standard error of the mean.

Analysis of pancreatic trypsin and chymotrypsin (respectively, EC 3.4.4.4 and EC 3.4.4.5) requires prior activation of the zymogens. The pancreas samples were incubated with $4 \%$ enterokinase (Sigma E1256) for $1 \mathrm{~h}$ at $25^{\circ} \mathrm{C}$ in Tris buffer ( $\mathrm{pH}$ 8.1) containing 20 $\mathrm{mM} \mathrm{CaCl}{ }_{2}$; that treatment gives reproducible maximal activation of the proteolytic zymogens (Brannon et al. 1987). Aliquots of $50 \mu \mathrm{L}$ were assayed to measure trypsin activity using DL-BAPNA (benzoyl-arginine-p-nitroanilide) $0.9 \mathrm{mM}$ solution as substrate at $\mathrm{pH} 8.1$ during $10 \mathrm{~min}$ at $40^{\circ} \mathrm{C}$. We used $\mathrm{pH} 8.1$ because that is the optimum for trypsin activity in House Sparrows (Caviedes-Vidal and Karasov 1995), and we used $10 \mathrm{~min}$ incubations because in preliminary tests with warbler intestine trypsin hydrolysis was linear with time up to at least $12 \mathrm{~min}$ (the longest we tested). The reaction was terminated by adding $0.25 \mathrm{~mL}$ of $3 \%$ acetic acid. The liberated amount of p-nitroanilide was estimated by reading the absorbance at $410 \mathrm{~nm}$ (Erlanger et al. 1961) and using a pnitroanilide standard curve. Chymotrypsin activities were also measured by the amount of p-nitroanilide released by hydrolysis of a GPNA (N-glutaryl-Lphenylalanine-p-nitroanilide) $1 \mathrm{mM}$ solution at $\mathrm{pH}$ $=7.6$ (the optimum in House Sparrows) and $40^{\circ} \mathrm{C}$. The reaction was terminated with $3 \%$ acetic acid solution and the absorbance of the mixture was measured at $410 \mathrm{~mm}$ (Erlanger et al. 1966).

We estimated concentration of total protein in our samples by the Bradford assay using the commercial Bio-Rad Protein Assay (Bio-Rad, catalog number 500-0006). Absorbances were read at $595 \mathrm{~nm}$ and crystalline bovine serum album was used standard.
Specific amylase activities are expressed as units normalized to measured tissue wet mass. Specific trypsin and chymotrypsin activities are expressed as micromoles p-nitroaniline liberated per minute per gram wet tissue. We calculated the summed hydrolysis activity of the whole pancreas, an index of the total hydrolysis capacity, by multiplying activity per gram tissue by the pancreas mass.

Specific activities were compared among diet groups by one-way analysis of variance (ANOVA) using SYSTAT software (Wilkinson 1992). Bartlett tests for homogeneity of group variances were all nonsignificant. Plots of residuals were inspected for both apparent normal distribution and outliers, and if necessary, data were log transformed and analyzed again so that studentized residuals were approximately normally distributed and always $<3$. Pancreas masses and summed hydrolysis activities were compared among diet groups by analysis of covariance (ANCOVA) using $\log$ (body mass) as a covariate. There were no significant interactions between diet groups and body mass in those analyses. A value of $P<0.05$ was considered significant, and $0.05<P<$ 0.1 was taken to indicate a trend.

Results and Discussion.-Initial body masses averaged $11.9 \pm 0.2 \mathrm{~g}(n=24)$ and did not differ significantly by diet group, but after 7 days on the diets, birds eating the seed diet tended to have lower body masses $(10.8 \pm 0.6)$ than those eating either insect diet $(11.9 \pm 0.2)$ or fruit diet $(12.5 \pm 0.3)$ (one-way ANOVA $F=3.23, \mathrm{df}=2$ and $21, P=0.060)$. The $\log$ (pancreas mass) was not significantly related to either $\log$ (body mass) (ANCOVA $F=2.43, \mathrm{df}=1$ and $20, P=0.13)$ or $\operatorname{diet}(F=0.93, \mathrm{df}=1$ and $20, P=$ $0.41)$.

Diet had no significant effect on the specific activities per gram pancreas of either chymotrypsin or amylase (Fig. 1, left column), although there was a trend for higher specific trypsin activity in birds eating seed $\operatorname{diet}(F=3.0, \mathrm{df}=2$ and $21, P=0.08)$. When trypsin-specific activity was log transformed to compensate for a possible outlier, the difference was signficant $(F=3.52, \mathrm{df}=2$ and $21, P=0.048)$. Although we present specific enzyme activity normalized to pancreatic wet mass, our data can be compared with those of other studies that normalize activity to pancreatic protein by dividing activities per unit wet mass by the pancreatic protein content. Pancreatic protein content did not differ significantly among the diet groups (ANOVA $F=0.28, \mathrm{df}=2$ and $21, P=0.76)$ and averaged $0.15 \pm 0.005 \mathrm{mg}$ protein per milligram pancreas $(n=24)$. As was the case for activity per milligram pancreas, diet had a significant effect on the specific activity per milligram protein for trypsin $(F=3.72, \mathrm{df}=2$ and $21, P=0.041)$ but no significant effect on specific activities per milligram protein of chymotrypsin or amylase (data not shown). Diet also had no significant effect on summed hydrolysis activity of the whole pancreas 

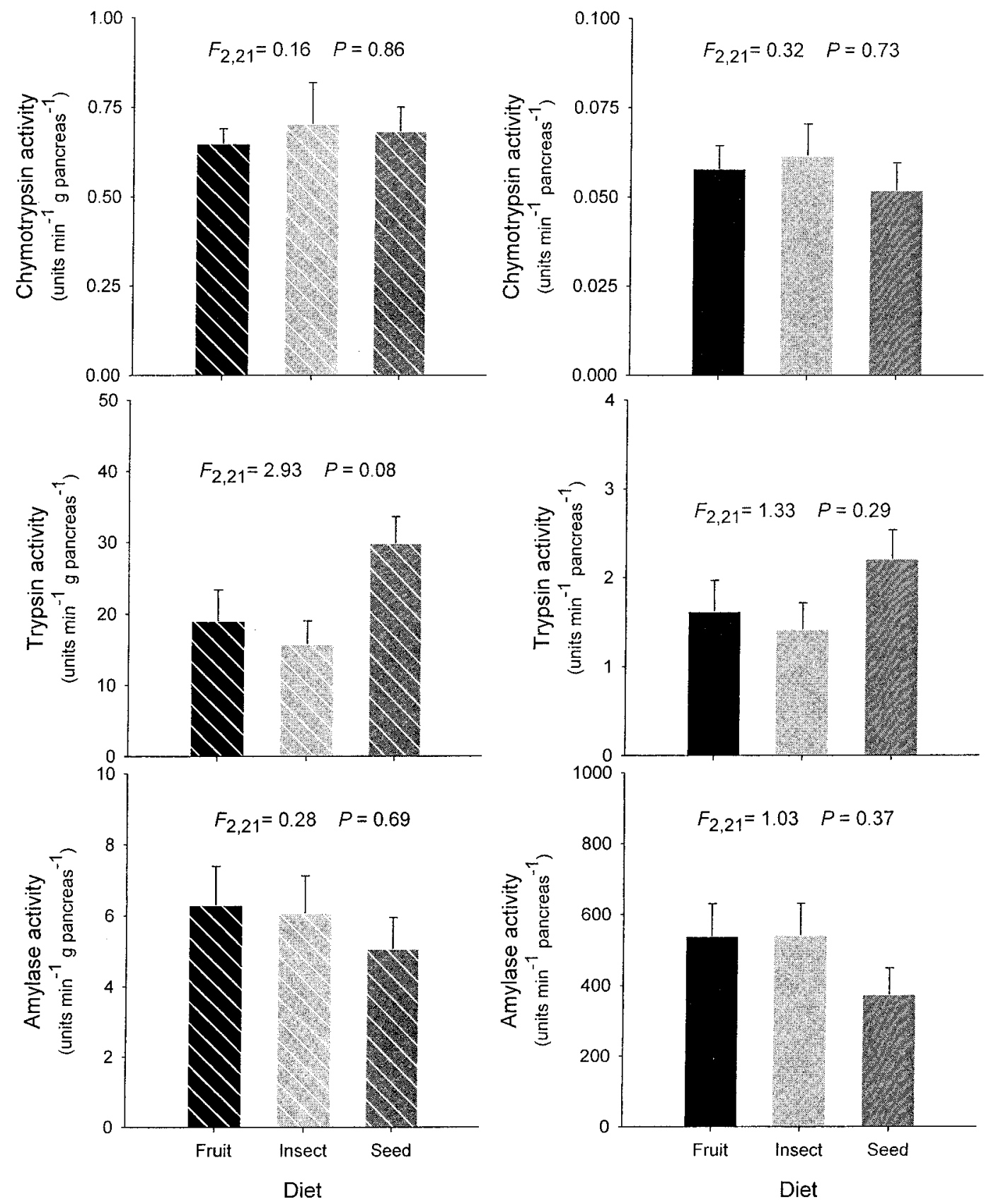

FIG. 1. Pancreatic enzyme activities as a function of diet in Yellow-rumped Warblers. The panels on the left are for activities per unit pancreatic wet mass of chymotrypsin (top), trypsin (middle) and amylase (bottom). Panels on the right are for total activities per pancreas. Bars in each panel show the mean enzyme activity \pm SE (actual, not least-squares-adjusted) for warblers habituated to the fruit diet $(n=10)$, insect diet $(n=7)$, or seed diet $(n=7)$. Each panel also includes the $F$-value (with degrees of freedom subscripted) and $P$-value from the ANOVA test for effect of diet. 
(Fig. 1, right column). Body mass was a significant covariate for summed activity of only one of the enzymes, chymotrypsin $(F=4.89, \mathrm{df}=1$ and $20, P=$ 0.039 ).

This study, and the complementary study on Pine Warblers (Levey et al. 1999), are the first to test for dietary modulation of pancreatic enzymes in omnivorous wild birds, to our knowledge. In chickens (Imondi and Bird 1967, Hulan and Bird 1972), and in laboratory rats, levels of amylase and proteases change in proportion to dietary content of their respective substrates, and increases of $5 \times$ have been observed for amylase, trypsin, and chymotrypsin activity (Brannon 1990). In Yellow-rumped Warblers, we failed to find the predicted pattern that pancreatic enzymes would be up-modulated by their respective substrates. Though our sample sizes were small and standard deviations large, we had sufficient power (at $\alpha=0.05$ and $\beta=0.2$; see above) to rule out that pancreatic enzyme activity increased by even $2 \times$. Though there was an increase in trypsin activity on the seed $\operatorname{diet}(P=0.08$ for untransformed data, $P<$ 0.05 for $\log$ transformed data) that was not the diet with the highest protein and thus not the predicted pattern. Birds eating seed diets tended to lose body mass, but the loss was not particularly large (approximately $-10 \%$ ) and did not cause declines in pancreas mass or enzymes, as occurs in food-restricted Yellow-rumped Warblers (Morris et al. 2001).

Apparent absence of modulation in Yellow-rumped Warblers was surprising for at least two reasons. First, diet differences were quite large for both carbohydrate $(73 \%$ carbohydrate for fruit diet vs. $\leq 17 \%$ for the other two diets) and protein (53\% protein for insect diet vs. $\leq 21 \%$ for the other two diets). Second congeneric Pine Warblers did exhibit some modulation. Specific amylase activity per gram pancreas was nearly a third higher in Pine Warblers eating fruit and seed diet than insect diet, and trypsin and chymotryspin specific activities were a quarter to a third higher in Pine Warblers eating insect diet compared with the other two diets (Levey et al. 1999). We did not have enough statistical power to discriminate changes of this magnitude. But we are struck with the fact that neither species showed substantial modulation. Neither Dendroica exhibits the magnitude of digestive biochemical modulation previously described in chickens (Imondi and Bird 1967, Hulan and Bird 1972), and laboratory rats (Brannon 1990). Also, both chickens and laboratory rats appear to have much greater capacity to tolerate a wide range of diets. In contrast, studies with both warblers showed them to be marginal digesters of starch at the whole-animal level (Afik and Karasov 1995, D. J. Levey pers. comm.), both warblers were unable to maintain body mass constant on the seed-based diet (this study, Afik et al. 1995, Afik and Karasov 1995, Levey et al. 1999), and Pine Warblers could not maintain body mass constant on the fruit diet (Levey et al.
1999, D. J. Levey pers. comm.). For Yellow-rumped Warblers, poor ability to utilize starch or the seedbased diet was manifest in captives throughout the year (Afik and Karasov 1995) and not just in individuals tested in the present study during the fall, the time of year when they would naturally be migrating. For warblers, it is interesting to speculate that they represent a case of only modest ability to modulate pancreatic enzymes, and that for some diets, they lack sufficient enzyme and hence are constrained in their dietary niche.

We do not think that the prolonged period of captivity ( 1 year) somehow retarded ability of the warblers to respond to the dietary manipulation, because the same birds did increase their intestinal aminopeptidase activity on the high-protein diet (Afik et al. 1995). Nor do we think that our seven-day diet habituation period was not long enough for pancreatic enzyme modulation. Though in the complementary study with Pine Warblers, many of the birds were habituated to the three diets for more than a month, we note that changes in pancreatic enzyme contents are apparent within $24 \mathrm{~h}$ after a dietary change in rats and chicks and are complete by 5-7 days (Karasov and Hume 1997). Some authors (Karasov 1996, Levey et al. 1999, Biviano et al. 1993) stated that there may be a longer time course for downward than upward regulation. In our study, expected direction of change was up-modulation for proteases in birds switched from fruit diet to insect diet, and downmodulation for amylase for birds switched from fruit diet to lower carbohydrate insect and seed diets. In neither situation did we see significant variation in enzyme activities. Despite our skepticism regarding inadequate time for dietary adjustment, future tests for modulation might include as well study of the time course for modulation.

It is possible that tests for changes in the enzyme and precursor activities in the pancreas are not good indices for modulation of pancreatic enzyme activity synthesis. Enzyme activity in the pancreas is the balance between synthesis and secretion, and greater release of enzyme(s) during digestion of a meal can result in lower activities of enzyme in the pancreas of chickens (Barash et al. 1993). One alternative is to measure enzyme mRNA levels as an index of synthesis rates, and measure pancreatic enzyme activity prior to the first meal of the day. Also, calculation of ratios of activity of different pancreatic enzymes might provide information on relative synthesis rates without the complicating factor of effect of secretion rate on absolute enzyme levels. However, when we calculated the ratios of amylase to either of the proteases in Yellow-rumped Warblers, there was still no significant diet treatment effect. Thus, we doubt that our diet treatments had a significant effect on relative rates of synthesis of different enzymes.

This is not the first instance in which we have failed to find in a wild species a pattern of modula- 
tion of digestive biochemistry that has been observed in domesticated species. In Yellow-rumped Warblers, for example, the intestinal brush border's carbohydrase activity and active glucose transport activity were not increased on the fruit diet (Afik et al. 1995, 1997), even though both increase in laboratory rats and mice fed high carbohydrate diets (Karasov and Hume 1997). More generally, with the exception of Pine Warbler, dietary modulation of intestinal carbohydrase activity has not been observed in any passerine species tested ( $n=5$ species; Caviedes-Vidal et al. 2000), though it has been observed in chickens (Biviano et al. 1993).

Whether such differences among species relate to domestication, phylogeny, or some other factor is unknown. Perhaps there has been increased selection in wild compared with domesticated omnivorous species for high constitutive enzyme levels because the foods of the former contain plant secondary metabolites capable of interfering with enzymatic digestion. That kind of adjustment occurs phenotypically in chicks fed trypsin inhibitors for a prolonged period of time (Green and Lyman 1972). In that regard, it was interesting that in Yellow-rumped Warblers there was an increase in trypsin activity on the seed $\operatorname{diet}(P=0.08)$, and some seeds do contain protease inhibitors, though we do not know about sunflower seeds in particular. Tests of that hypothesis at an evolutionary scale, or other hypotheses regarding differences related to phylogeny, require a multispecies data set analyzed within a phylogenetic context (Harvey and Pagel 1991). Thus, we look forward to additional studies of regulation of digestive biochemistry. Considering the two primarily insectivore-frugivore Dendroica species already tested (this study, Levey et al. 1999) and the complicating issues highlighted above, future studies might test for modulation in wild granivore-insectivores at different times after diet switches, and measure either mRNA levels or at least ratios of activity of carbohydrate, fat, or protein digesting pancreatic enzymes.

Acknowledgments. - We thank Juan Chediack and Carlos Codorniu for their logistic support in the laboratory. The work was supported by grants from Universidad Nacional de San Luis and FONCYT PICT98 01-3101 to E.C.-V., National Science Foundation Grant IBN-9318675 and 9723793 to W. H. K., and the A. W. Schorger Fund and the Max McGraw Wildlife Foundation.

\section{LiterATURE Cited}

Afik, D., E. Caviedes-Vidal, C. Martínez del Rio, AND W. H. KARASOV. 1995. Dietary modulation of intestinal hydrolytic enzymes in Yellow-rumped Warblers. American Journal of Physiology 269:R413-R420.

AfIK, D., B. W. DARKEN, AND W. H. KARASOv. 1997. Is diet-shifting facilitated by modulation of in- testinal nutrient uptake? Test of an adaptational hypothesis in Yellow-rumped Warblers. Physiological Zoology 70:213-221.

AfIK, D., AND W. H. Karasov. 1995. The trade-offs between digestion rate and efficiency in warblers and their ecological implications. Ecology 76:2247-2257.

BARASH, I., Z. NITSAN, AND I. NIR. 1993. Adaptation of light-bodied chicks to meal feeding: Gastrointestinal tract and pancreatic enzymes. British Poultry Science 34:35-42.

Biviano, A. B., C. Martínez Del Rio, and D. L. PhILlips. 1993. Ontogenesis of intestine morphology and intestinal disaccharidases in chickens (Gallus gallus) fed contrasting purified diets. Journal of Comparative Physiology B 163:508518.

BRANNON, P. M. 1990. Adaptation of the exocrine pancreas to diet. Annual Review of Nutrition 10: 85-105.

Brannon, P. M., V. P. Collins, AND M. Kore. 1987. Alterations of pancreatic digestive enzyme contents in the manganese deficient rat. Journal of Nutrition 117:305-311.

Caviedes-Vidal, E., D. AfiK, C. Martínez del Rio, AND W. H. KARASOV. 2000. Dietary modulation of intestinal enzymes of the House Sparrow (Passer domesticus): Testing an adaptive hypothesis. Comparative Biochemistry and Physiology A 125:11-24.

Caviedes-Vidal, E., AND W. H. Karasov. 1995. Influences of diet composition on pancreatic enzyme activities in House Sparrows. American Zoologist 35:78A.

CoHen, J. 1988. Statistical Power Analysis for the Behavioral Sciences. Lawrence Erlbaum Associates, Hillsdale, New Jersey.

DAlquist, A. 1962. A method for the determination of amylase. Scandinavian Journal of Clinical Investigation 14:145-157.

Denslow, J. S., D. J. Levey, T. C. Moermond, And B. C. Wentworth. 1987. A synthetic diet for fruiteating birds. Wilson Bulletin 99:131-134.

Erlanger, B. F., F. Adel, AND G. A. Cooper. 1966. Action of chymotrypsin on two new chromogenic substrates. Archives of Biochemistry and Biophysics 115:206-210.

ERlANGer, B. F., N. KOKOVSKY, AND W. COHEN. 1961. Preparation and properties of two new chromogenic substrates of trypsin. Archives of Biochemistry and Biophysics 95:271-278.

Green, G. M., AND R. L. Lyman. 1972. Feedback regulation of pancreatic enzyme secretion as a mechanism for trypsin inhibitor-induced hypersecretion in rats. Proceedings of the Society for Experimental Biology and Medicine 140:6-12.

GryJ, E., C. MARTínez del Rio, AND I. BAKer. 1990. Avian pollination and nectar use in Combretum fruticosum (Loefl.). Biotropica 22:266-271. 
Harvey, P. H., And M. D. Pagel. 1991. The Comparative Method in Evolutionary Biology. Oxford University Press, Oxford.

HJorTH, J. P. 1979. Genetic variation in mouse salivary amylase rate synthesis. Biochemical Genetics 17:665-682.

Hulan, H. W., AND F. H. BiRD. 1972. Effect of fat level in isonitrogenous diets on the composition of avian pancreatic juice. Journal of Nutrition 102: 459-468.

IMONDI, A. R., AND F. H. BIRD. 1967. Effects of dietary protein level on growth and proteolytic activity of the avian pancreas. Journal of Nutrition 91: 421-428.

Karasov, W. H. 1996. Digestive plasticity in avian energetics and feeding ecology. Pages 61-84 in Avian Energetics and Nutritional Ecology (C. Carey, Ed.). Chapman and Hall, New York.

Karasov, W. H., AND I. D. HumE. 1997. Vertebrate gastrointestinal system. Pages 409-480 in Hand- book of Comparative Physiology (W. Dantzler, Ed.). American Physiological Society, Bethesda, Maryland.

Levey, D. J., A. R. Place, P. J. Rey, and C. Martínez DEL RIO. 1999. An experimental test of dietary enzyme modulation in Pine Warblers Dendroica pinus. Physiological and Biochemical Zoology 72:576-587.

Morris, K. A., W. H. Karasov, AND E. Caviedes-VIDAL. 2001. Does digestive physiology limit refueling rates in migratory Yellow-rumped Warblers (Dendroica coronata)? American Zoologist. 40:1139 [Abstract].

WILKINSON, L. 1992. SYSTAT for Windows. SYSTAT Inc., Evanston, Illinois.

YARBRough, C. G., AND D. W. Johnston. 1965. Lipid deposition in wintering and premigratory Myrtle Warblers. Wilson Bulletin 77:175-191.

Received 6 October 2000, accepted 15 March 2001.

Associate Editor: C. Blem 